\title{
The association between the neutrophil/lymphocyte ratio and functional capacity in patients with idiopathic dilated cardiomyopathy
}

\author{
Abdulkadir Yıldız, Murat Yüksel, Mustafa Oylumlu, Nihat Polat, Mehmet Ata Akıl, Halit Acet \\ Department of Cardiology, Faculty of Medicine, Dicle University, Diyarbakır-Turkey
}

\section{ABSTRACT}

Objective: The neutrophil/lymphocyte ratio (NLR) is an inexpensive, readily available and reliable inflammatory marker, which has a predictor value in different cardiovascular disorders. Functional capacity is one of the most important prognostic factors in patients with heart failure, which is usually stated as metabolic equivalents (MET). The goal of the study was to investigate the relationship between the NLR and functional capacity (FC) in patients with idiopathic dilated cardiomyopathy (IDC).

Methods: Treadmill test according to modified-Bruce protocol was performed in 37 patients with IDC (mean age $46.7 \pm 11.7$ years, $81.1 \%$ male) to assess their functional capacity. Baseline clinical and echocardiographic variables were obtained. Hematological and biochemical parameters were measured using standard techniques.

Results: The patients were divided into low $(<5 \mathrm{MET}, \mathrm{n}=18)$ and high ( $>5 \mathrm{MET}, \mathrm{n}=19) \mathrm{FC}$ groups according to their functional status in the exercise test. The 2 groups were similar regarding age, gender and the presence of hypertension and diabetes mellitus. There was no significant difference between groups regarding echocardiographic parameters such as left ventricular ejection fraction and diameters. However, the NLR was significantly higher in low FC group compared to high FC group ( $3.62 \pm 2.24$ vs. $2.24 \pm 0.67, p=0.002$; respectively). There were significant negative correlations between the NLR, MET and left ventricular ejection fraction ( $r=-0.405, p=0.013$ and $r=-0.028, p=0.028$; respectively). Diastolic dysfunction was present in all the patients with low functional capacity. A cut-off point of 2.26 for the NLR had $83 \%$ sensitivity and $69 \%$ specificity in predicting poor FC. After multivariate analysis, only the NLR remained significant predictor of poor functional status.

Conclusion: We detected a significant association between the NLR and low FC, both of which has predictive and prognostic value in patients with heart failure. Functional capacity may depend on diastolic function rather than left ventricular ejection fraction in patients with IDC.

(Anatolian J Cardiol 2015; 15: 13-7)

Key words: idiopathic dilated cardiomyopathy, neutrophil/lymphocyte ratio, heart failure, functional capacity

\section{Introduction}

Heart failure (HF) occurs frequently in the clinical practice as a public health problem with high morbidity and mortality despite advances in pharmacological and device-dependent treatments. About $50 \%$ of the patients with dilated cardiomyopathy, the most common form of the cardiomyopathies, have no underlying etiology whereas 25 to $35 \%$ of them have familial inheritance (1). The patients with dilated cardiomyopathy may present to the outpatient clinics with various clinical courses ranging from asymptomatic left ventricular dysfunction to serious congestive heart failure.
Functional capacity (FC) is one of the most important prognostic factors in patients with heart failure, which is usually stated as metabolic equivalents (MET) according to the treadmill test.

Usage of hematological parameters as predictive and prognostic markers in various cardiovascular diseases has been intensively investigated in recent years (2-5). Of these parameters, the neutrophil/lymphocyte ratio (NLR) has become prominent as a marker of underlying inflammation. Our objective in the present study was to investigate the relationship between the hematological parameters and $\mathrm{FC}$ in patients with idiopathic dilated cardiomyopathy (IDC). 


\section{Methods}

\section{Study population}

Patients with normal sinus rhythm who were diagnosed as IDC with left ventricular ejection fraction (LVEF) $<40 \%$, left ventricular diastolic diameter (LVDD) $>60 \mathrm{~mm}$ and presented to outpatient clinics of the cardiology department Faculty of Medicine, Dicle University, Diyarbakır were included prospectively. The diagnosis of IDC was based on patient history, physical examination, electrocardiogram, telecardiogram, echocardiography, and coronary angiography. All the patients were on ß-blocker, angiotensin converting enzyme inhibitor / angiotensin receptor blocker and diuretic treatment. All patients underwent symptom-limited treadmill test based on modified Bruce protocol to determine FC. Investigations for hematological and biochemical parameters were performed by standard methods. The patients with atrial fibrillation-flutter, coronary arterial disease, primary valvular pathology, advanced chronic obstructive pulmonary disease, cardiac cachexia (weight loss of $>7.5 \%$ of the previous normal weight over a period of $>6$ months) (6) and persistent biventricular cardiac pacemaker were excluded from the study. All patients gave an informed consent and local Ethics Committee approved the study.

\section{Echocardiographic analysis}

Left ventricular dimensions and wall thickness were measured from M-mode tracings on parasternal long-axis view according to the recommendations of the American Society of Echocardiography by using a commercially available ultrasound system (VIVID 7, GE Vingmed Ultrasound, Horten, Norway). Left ventricular ejection fraction was measured using the modified Simpson method on apical four-chamber view. For evaluation of left ventricular diastolic function, the mitral inflow pattern was evaluated from an apical four-chamber view with the sample volume placed at the mitral valve tips to acquire early diastolic (E), late diastolic (A) flow velocities, and E/A ratio. Tissue Doppler imaging was assessed by placing a sample volume at the mitral (septal and lateral) annulus to obtain early diastolic $\left(E^{\prime}\right)$, late diastolic $\left(A^{\prime}\right)$ velocities and $E^{\prime} / A^{\prime}$ ratio.

\section{Statistical analysis}

SPSS 16 software (SPSS Inc, Chicago, Illinois, USA) was used for analysis of the data. Normal distribution of continuous variables was tested using Kolmogorov-Smirnov and ShapiroWilk tests. Descriptive statistics were expressed as mean \pm standard deviation for continuous variables and nominal variables as number of cases and percentage (\%). Continuous variables with normal distribution were compared using Student's t test and those without normal distribution were compared using Mann-Whitney's U test. Chi-square test or Fischer's exact test was used to compare the categorical variables. Correlation analyses were made using Spearman test. Multivariate logistic regression analysis was performed to assess the independent predictors of poor $\mathrm{FC}$ and results were shown as odds ratio (OR) with $95 \%$ confidence intervals (Cls). Receiver-operating characteristic (ROC) curve analysis was used to determine the optimum cut-off levels of the NLR in association with poor FC. Significance level of the obtained data was commented statistically using the " $p$ " value. A p values $<0.05$ were considered as statistically significant.

\section{Results}

The present study included 37 patients with IDC whose mean age was $46.7 \pm 11.7$ years and $81.1 \%$ was male. The patients were divided into two groups as those with MET $\leq 5$ and those with MET $>5$ by the results of treadmill test based on modified Bruce method. Distribution of the baseline characteristics and echocardiographic data obtained by statistical analyses among the groups was summarized in Table 1.

Table 1. Demographic characteristics, hematological and echocardiographic parameters of the functional capacity groups

\begin{tabular}{|c|c|c|c|}
\hline Variables & $\begin{array}{l}<5 \text { MET } \\
(n=18)\end{array}$ & $\begin{array}{l}>5 \text { MET } \\
(n=19)\end{array}$ & $P$ \\
\hline Age, years & $46.7 \pm 12.6$ & $46.7 \pm 11.2$ & 0.992 \\
\hline Male gender, n (\%) & $16(88.9)$ & $14(73.7)$ & 0.405 \\
\hline Hypertension, $n(\%)$ & $4(22.2)$ & $6(31)$ & 0.714 \\
\hline Diastolic dysfunction, n (\%) & $18(100)$ & $13(68.4)$ & 0.020 \\
\hline Diabetes mellitus, $\mathrm{n}(\%)$ & $4(22.2)$ & $3(15.8)$ & 0.693 \\
\hline Body mass index, $\mathrm{kg} / \mathrm{m}^{2}$ & $25.2 \pm 2.8$ & $27.1 \pm 5.0$ & 0.161 \\
\hline Glucose, $\mathrm{mg} / \mathrm{dL}$ & $101 \pm 16$ & $109 \pm 33$ & 0.365 \\
\hline Urea, mg/dL & $42 \pm 7$ & $38 \pm 11$ & 0.137 \\
\hline Creatinine, $\mathrm{mg} / \mathrm{dL}$ & $0.97 \pm 0.17$ & $0.97 \pm 0.28$ & 0.973 \\
\hline Hemoglobin, gr/dL & $13.1 \pm 3.4$ & $14.4 \pm 1.2$ & 0.132 \\
\hline Platelet, $/ \mathrm{mm}^{3}$ & $262 \pm 98$ & $241 \pm 55$ & 0.424 \\
\hline White blood cell count, $x 10^{3} / \mu \mathrm{L}$ & $8.77 \pm 1.72$ & $7.88 \pm 1.82$ & 0.135 \\
\hline Neutrophil count, $x 10^{3} / \mu \mathrm{L}$ & $5.98 \pm 1.43$ & $4.68 \pm 1.18$ & 0.005 \\
\hline 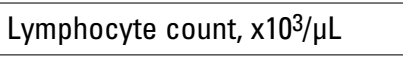 & $1.94 \pm 0.74$ & $2.19 \pm 0.66$ & 0.286 \\
\hline Neutrophil/ Lymphocyte ratio & $3.62 \pm 2.24$ & $2.24 \pm 0.67$ & 0.002 \\
\hline $\begin{array}{l}\text { Left ventricular diastolic } \\
\text { diameter, } \mathrm{mm}\end{array}$ & $67.5 \pm 6.7$ & $65.3 \pm 4.6$ & 0.463 \\
\hline $\begin{array}{l}\text { Left ventricular systolic } \\
\text { diameter, mm }\end{array}$ & $59.8 \pm 7.9$ & $58.3 \pm 6.2$ & 0.903 \\
\hline $\begin{array}{l}\text { Left ventricular ejection } \\
\text { fraction, } \%\end{array}$ & $26 \pm 7$ & $28 \pm 7$ & 0.426 \\
\hline Evelocity, $\mathrm{m} / \mathrm{s}$ & $0.99 \pm 0.19$ & $0.97 \pm 0.20$ & 0.745 \\
\hline A velocity, $\mathrm{m} / \mathrm{s}$ & $0.76 \pm 0.40$ & $0.70 \pm 0.21$ & 0.584 \\
\hline E/A ratio & $1.66 \pm 0.79$ & $1.50 \pm 0.50$ & 0.469 \\
\hline $\mathrm{E}^{\prime}$ velocity, $\mathrm{m} / \mathrm{s}$ & $0.065 \pm 0.011$ & $0.076 \pm 0.023$ & 0.067 \\
\hline$A^{\prime}$ velocity, $\mathrm{m} / \mathrm{s}$ & $0.090 \pm 0.012$ & $0.078 \pm 0.017$ & 0.017 \\
\hline$E^{\prime} / A^{\prime}$ ratio & $0.723 \pm 0.081$ & $1.049 \pm 0.473$ & 0.008 \\
\hline
\end{tabular}




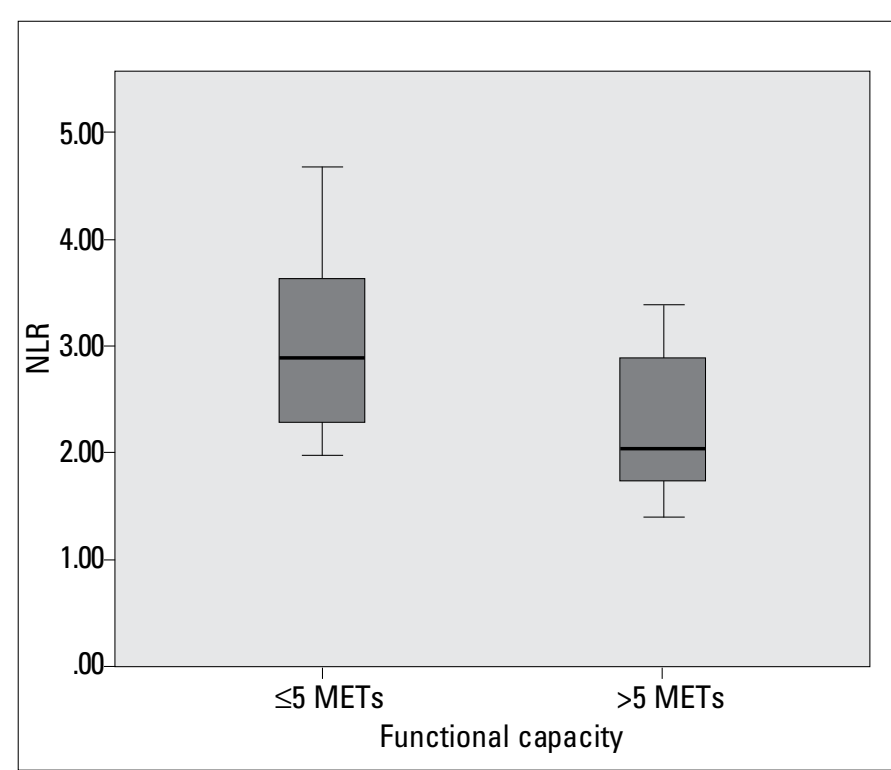

Figure 1. Neutrophil/lymphocyte ratio levels according to functional capacity groups

Table 2. Echocardiographic diastolic function parameters of the patients according to the functional status

\begin{tabular}{|l|c|c|c|}
\hline Parameters & $\mathbf{5}$ METS & $>\mathbf{5}$ METS & $\boldsymbol{P}$ \\
\hline E velocity, m/s & $0.99 \pm 0.19$ & $0.97 \pm 0.20$ & 0.745 \\
\hline A velocity, m/s & $0.76 \pm 0.40$ & $0.70 \pm 0.21$ & 0.584 \\
\hline E/A & $1.66 \pm 0.79$ & $1.50 \pm 0.50$ & 0.469 \\
\hline E' velocity, m/s $^{\prime}$ & $0.065 \pm 0.011$ & $0.076 \pm 0.023$ & 0.067 \\
\hline A $^{\prime}$ velocity, m/s & $0.090 \pm 0.012$ & $0.078 \pm 0.017$ & 0.017 \\
\hline E'$^{\prime} / \mathrm{A}^{\prime}$ & $0.723 \pm 0.081$ & $1.049 \pm 0.473$ & 0.008 \\
\hline E/E' & $15.61 \pm 3.95$ & $13.86 \pm 5.28$ & 0.264 \\
\hline
\end{tabular}

The groups were similar in terms of age, gender, and presence of diabetes or hypertension. There was no statistically significant difference between the groups in echocardiographic parameters such as LVEF or left ventricular diameters. Of the hematological parameters, the NLR was significantly higher in the group of MET $\leq 5$ than in the group of MET $>5$ ( $p=0.002$, Fig. 1). All patients in the group of low FC had diastolic dysfunction $(p=0.020)$. Among diastolic function parameters (Table 2$)$, mean $A^{\prime}$ velocity and $E^{\prime} / A^{\prime}$ ratio were significantly different between groups ( $p=0.017$ and $p=0.008$; respectively).

The relationship between exercise and echocardiographic parameters and the NLR was examined with correlation analysis (Table 3). However, there was no significant correlation between echocardiographic and exercise test parameters. Exercise duration had no correlation with LVEF ( $r=-0.059$, $\mathrm{p}=0.729)$ and $\operatorname{LVDD}(\mathrm{r}=-0.013, \mathrm{p}=0.941)$; and METs showed no association with $\operatorname{LVEF}(r=0.071, p=0.678)$ and $\operatorname{LVDD}(r=-0.063$, $\mathrm{p}=0.712$ ). After multivariate regression analysis, the NLR remained significant predictor of poor FC (Table 4). Receiver operating characteristics $(\mathrm{ROC})$ curves explored the relation-
Table 3. Spearman correlation analysis to assess the association of NLR with echocardiographic and exercise parameters

\begin{tabular}{|l|c|c|c|c|l|}
\hline & LVDD & LVSD & LVEF & $\begin{array}{l}\text { Exercise } \\
\text { Duration }\end{array}$ & MET \\
\hline NLR & 515 & 0.473 & -0.361 & -0.458 & -0.405 \\
\hline Correlation coefficient & 5.001 & 0.003 & 0.028 & 0.004 & 0.013 \\
\hline$P$ & 0.06 rentricular ejection fraction; \\
\hline $\begin{array}{l}\text { LVDD - left ventricular diastolic diameter; LVEF - left ventric } \\
\text { LVSD - left ventricular systolic diameter; MET - metabolic equivalent; NLR - neutrophil/ } \\
\text { lymphocyte ratio }\end{array}$
\end{tabular}

Table 4. Multivariate regression analysis to predict poor functional capacity

\begin{tabular}{|l|c|c|c|}
\hline Variables & Odds ratio & 95\% Confidence interval & $\boldsymbol{P}$ \\
\hline NLR & 3.934 & $1.024-15.123$ & 0.046 \\
\hline$E^{\prime} / A^{\prime}$ & 0.089 & $0.000-1.788$ & 0.089 \\
\hline NLR - neutrophil/lymphocyte ratio \\
\hline
\end{tabular}

ship between the NLR and FC. Using a cut point of 2.26, the NLR predicted poor $\mathrm{FC}$ with a sensitivity of $83 \%$ and specificity of $69 \%$ (ROC area under curve: $0.804,95 \% \mathrm{Cl}: 0.663-0.945, \mathrm{p}=0.002$; Fig. 2).

\section{Discussion}

In the present study, a significant relationship was found between increased NLR and poor FC. Furthermore, the NLR showed negative correlation with exercise duration, MET and LVEF, and positive correlation with LVDD and LVSD. Using a cut point of 2.26 , the NLR predicted poor FC with a sensitivity of $83 \%$ and specificity of $69 \%$.

Idiopathic dilated cardiomyopathy is an inflammatory disease with many circulating active cytokines being involved in the pathogenesis. Although the mechanisms responsible for the development of IDC are not fully understood, high production of inflammatory cytokines in leukocytes of patients with IDC and the presence of interleukin-6 (IL-6) and tumor necrosis factoralpha (TNF- $\alpha$ ) in cardiac tissue suggest an inflammatory component in the disease development and progression (7).

Being one of the prognostic indicators in heart failure, $\mathrm{FC}$ is usually classified using New York Heart Association (NYHA) classification. However, because of the subjective nature of the NYHA classification, treadmill exercise test was used in the present study to determine functional capacity. The best objective method to determine functional capacity is the peak $\mathrm{O}_{2}$ consumption $\left(\mathrm{VO}_{2}\right)$ measured by cardiopulmonary exercise test, and it is used as one of the most powerful independent mortality predictors in patients with heart failure with serious left ventricular dysfunction (8-13). However, the equipment required for cardiopulmonary exercise test is not always available and requires expertise. So, it is not routinely applied in many centers. 


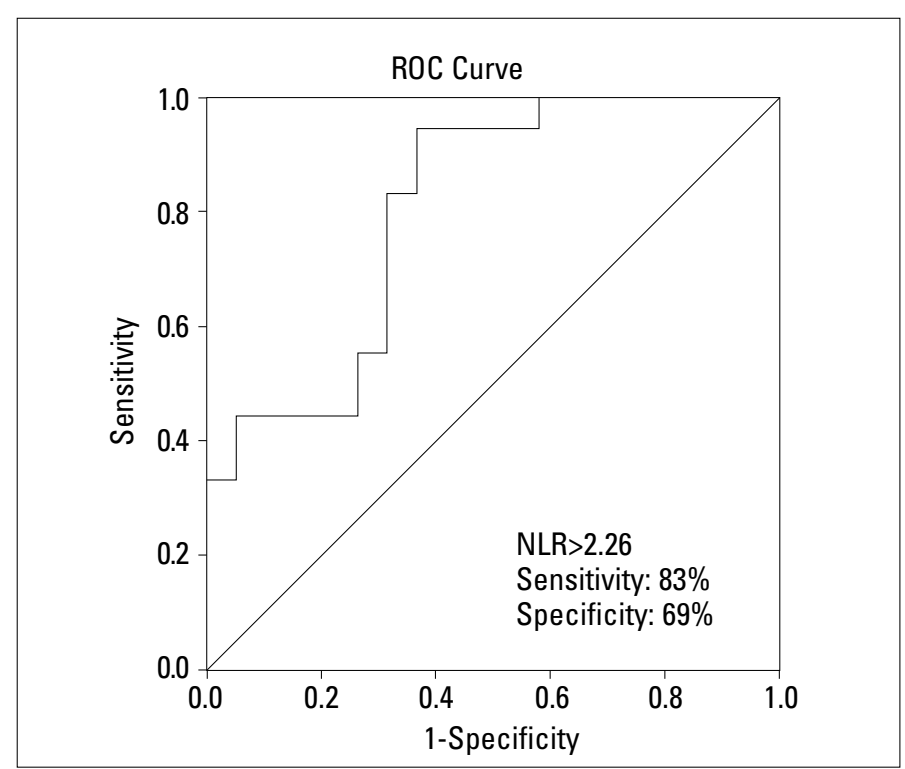

Figure 2. Receiver operating characteristics curve of neutrophil-tolymphocyte (NLR) for predicting poor functional capacity

Instead of it, exercise capacity is usually measured indirectly and expressed as metabolic equivalent (MET) (14). Functional capacity measured as MET is a powerful indicator of cardiovascular mortality (15-17). A study by Hsich et al. (17) showed that shortening of one minute in exercise duration (about $0.5 \mathrm{MET}$ ) based on Naughton protocol cause increase of $7 \%$ in mortality. According to this relationship confirmed by other studies, increase of $1 \mathrm{MET}$ in exercise capacity is associated with 10 to $25 \%$ reduction in mortality $(15,18-22)$.

As well known, there is usually an inconsistency between $\mathrm{FC}$, which is an independent predictor of mortality, and conventional echocardiographic parameters such as LVEF, LVDD, and LVSD in the patients with heart failure. Previous studies emphasized that no correlation existed between exercise capacity and parameters of left ventricular function (23-25). In a study conducted on patients with left ventricular dysfunction, functional capacity was found to be related to catabolism and inflammatory status while its relationship with LVEF wasn't demonstrated (26). Lymphocytes represent a more appropriate immune response while neutrophils causing an uncontrolled inflammatory reaction (27). So we hypothesized that in patients with IDC there may be a relation between functional impairment and increased NLR, which shows the balance between destructive and controlled inflammatory responses. Inflammation has been shown to play an important role in the progression and severity of the atherosclerotic disease in many studies $(4,28,29)$. In patients with $\mathrm{HF}$, high level of inflammatory markers is associated with poor prognosis (3). In the present study we found that the NLR, which is an inexpensive, easily accessible and reliable marker of inflammatory condition, was higher in the group with low FC. Additionally, the NLR also showed significant correlation with echocardiographic parameters such as LVEF and LVDD, both of which showed no correlation with exercise parameters.
However, the NLR was found to be negatively related to exercise duration $(r=-0.458, p=0.004)$ as well as METs $(r=-0.405, p=0.013)$ independent of left ventricular size and ejection fraction. In a study conducted by Windram et al. (30) on patients with low ejection fraction, inflammatory markers were found to be related with functional capacity but not with LVEF. Also in another study $\mathrm{FC}$, measured by $\mathrm{VO}_{2}$, has poor correlation with resting LVEF in patients with IDC (31). Our results were consistent with the literature. Another interesting result of the present study was that all patients in the lower FC group had diastolic dysfunction. Parallel to the our results, peak $\mathrm{VO}_{2}$ was found to be better correlated to diastolic filling rather than systolic LV function in patients with IDC (32). Mean $A^{\prime}$ and $E^{\prime} / A^{\prime}$ ratio were different between $\mathrm{FC}$ groups. Frequently being overlooked in clinical and echocardiographic practice, diastolic dysfunction was related to $\mathrm{FC}$ in contrast to LVEF. Although $\mathrm{E}^{\prime} / \mathrm{A}^{\prime}$ ratio has lost its significance after multivariate analysis, we believe that this issue should be evaluated by prospective large-scale studies.

\section{Study limitations}

The study was single-centered and included low number of patients. Because of the sample size and inadequate power, it is possible that some associations were not detected. Functional capacity was used as prognostic indicator in the present study but true prognostic follow-up of the patients was not performed. Other inflammatory parameters such as IL-6 or TNF- $\alpha$ were not measured simultaneously because of the cost and not immediately available in daily practice. Furthermore, in the assessment of $\mathrm{FC}$ cardiopulmonary exercise testing was not performed due to the inadequate equipment, however, exercise test according to modified Bruce protocol was chosen for its simplicity, frequent use in earlier studies and the fact that the correlation of its results with peak oxygen uptake as measured. As this was a cross-sectional study, we could not determine whether better FC might be explained by less inflammation. Further prospective studies enrolling larger cohorts of patients are needed to confirm the prognostic role of inflammatory markers in patients with IDC.

\section{Conclusion}

In conclusion, the NLR and presence of diastolic dysfunction may be deterministic in differentiating the patients with IDC who has similar echocardiographic parameters of systolic function with good and limited FC.

Conflict of interest: None declared.

Peer-review: Externally peer-reviewed.

Acknowledgement: We are grateful to Dicle University DUBAP for their sponsorship about English editing of this manuscript. 
Authorship contributions: Concept - A.Y.; Design - A.Y.; Supervision - A.Y.; Resource- M.0.; Material - M.0.; Data collection \&/or processing - M.Y.; Analysis \&/or interpretation - M.Y.; Literature search - N.P.; Writing - A.Y., M.A.A.; Critical review - H.A.

\section{References}

1. Gallo P, d'Amati G. Cardiomyopathies. In, Silver MD, Gotlieb Al, Schoen FJ. Cardiovascular Pathology, 3rd edition. Churchill Livingstone, New York. 2001.p.285-325.

2. Arıbaş A, Akıllı H, Gül EE, Kayrak M, Demir K, Duman C, et al. Can neutrophil/lymphocyte ratio predict recurrence of non-valvular atrial fibrillation after cardioversion? Anadolu Kardiyol Derg 2013; 13: $123-30$.

3. Uthamalingam S, Patvardhan EA, Subramanian S, Ahmed W, Martin W, Daley M, et al. Utility of the neutrophil to lymphocyte ratio in predicting long-term outcomes in acute decompensated heart failure. Am J Cardiol 2011; 107: 433-8. [CrossRef]

4. Kaya H, Ertaş F, Islamoğlu Y, Kaya Z, Atılgan ZA, Çil H, et al. Association between neutrophil to lymphocyte ratio and severity of coronary artery disease. Clin Appl Thromb Hemost 2014; 20: 50-4. [CrossRef]

5. Işık T, Ayhan E, Uyarel H, Tanboğa IH, Kurt M, Uluganyan M, et al. Association of neutrophil to lymphocyte ratio with presence of isolated coronary artery ectasia. Turk Kardiyol Dern Ars 2013; 41: 123-30. [CrossRef]

6. Steinborn W, Anker SD. Cardiac Cachexia: Pathophysiology and clinical implications. Basic Appl Myol 2003; 13: 191-201.

7. Högye $M$, Mándi $Y$, Csanády $M$, Sepp R, Buzás K. Comparison of circulating levels of interleukin- 6 and tumor necrosis factor-alpha in hypertrophic cardiomyopathy and in idiopathic dilated cardiomyopathy. Am J Cardiol 2004; 94: 249-51. [CrossRef]

8. Cohn JN, Johnson GR, Shabetai R, Loeb H, Tristani F, Rector T, et al. Ejection fraction, peak exercise oxygen consumption, cardiothoracic ratio, ventricular arrhythmias, and plasma norepinephrine as determinants of prognosis in heart failure. The V-HeFT VA Cooperative Studies Group. Circulation 1993; 87: VI5-16.

9. Itoh H, Taniguchi K, Koike A, Doi M. Evaluation of severity of heart failure using ventilatory gas analysis. Circulation 1990; 81: 31-7.

10. Mancini DM, Eisen H, Kussmaul W, Mull R, Edmunds LH Jr, Wilson $J R$. Value of peak exercise oxygen consumption for optimal timing of cardiac transplantation in ambulatory patients with heart failure. Circulation 1991; 83: 778-86. [CrossRef]

11. Parameshwar J, Keegan J, Sparrow J, Sutton GC, Poole-Wilson PA. Predictors of prognosis in severe chronic heart failure. Am Heart $J$ 1992; 123: 421-6. [CrossRef]

12. Szlachcic J, Massie BM, Kramer BL, Topic N, Tubau J. Correlates and prognostic implication of exercise capacity in chronic congestive heart failure. Am J Cardiol 1985; 55: 1037-42. [CrossRef]

13. Vanhees L, Fagard R, Thijs L, Staessen J, Amery A. Prognostic significance of peak exercise capacity in patients with coronary artery disease. J Am Coll Cardiol 1994; 23: 358-63. [CrossRef]

14. Fleg JL, Pina IL, Balady GJ, Chaitman BR, Fletcher B, Lavie C, et al. Assessment of functional capacity in clinical and research applications: An advisory from the Committee on Exercise, Rehabilitation, and Prevention, Council on Clinical Cardiology, American Heart Association. Circulation 2000; 102: 1591-7. [CrossRef]

15. Myers J, Prakash M, Froelicher V, Do D, Partington S, Atwood JE. Exercise capacity and mortality among men referred for exercise testing. N Engl J Med 2002; 346: 793-801. [CrossRef]
16. Myers J. Exercise capacity and prognosis in chronic heart failure. Circulation 2009; 119: 3165-7. [CrossRef]

17. Hsich E, Gorodeski EZ, Starling RC, Blackstone EH, Ishwaran H, Lauer MS. Importance of treadmill exercise time as an initial prognostic screening tool in patients with systolic left ventricular dysfunction. Circulation 2009; 119: 3189-97. [CrossRef]

18. Spin JM, Prakash M, Froelicher VF, Partington S, Marcus R, Do D, et al. The prognostic value of exercise testing in elderly men. Am J Med 2002; 112: 453-9. [CrossRef]

19. Mora S, Redberg RF, Cui Y, Whiteman MK, Flaws JA, Sharrett AR, et al. Ability of exercise testing to predict cardiovascular and all-cause death in asymptomatic women: a 20-year follow-up of the lipid research clinics prevalence study. JAMA 2003; 290: 1600-7. [CrossRef]

20. Kokkinos P, Myers J, Kokkinos JP, Pittaras A, Narayan P, Manolis A, et al. Exercise capacity and mortality in black and white men. Circulation 2008; 117: 614-22. [CrossRef]

21. Franklin BA. Fitness: the ultimate marker for risk stratification and health outcomes? Prev Cardiol 2007; 10: 42-6. [CrossRef]

22. Goraya TY, Jacobsen SJ, Pellikka PA, Miller TD, Khan A, Weston $\mathrm{SA}$, et al. Prognostic value of treadmill exercise testing in elderly persons. Ann Intern Med 2000; 132: 862-70. [CrossRef]

23. Franciosa JA, Park M, Levine TB. Lack of correlation between exercise capacity and indexes of resting left ventricular performance in heart failure. Am J Cardiol 1981; 47: 33-9. [CrossRef]

24. Franciosa JA, Ziesche S, Wilen M. Functional capacity of patients with chronic left ventricular failure. Relationship of bicycle exercise performance to clinical and hemodynamic characterization. Am J Med 1979; 67: 460-6. [CrossRef]

25. Higginbotham MB, Morris KG, Conn EH, Coleman RE, Cobb FR. Determinants of variable exercise performance among patients with severe left ventricular dysfunction. Am J Cardiol 1983; 51: 52-60. [CrossRef]

26. Thierer J, Acosta A, Vainstein N, Sultan M, Francesia A, Marino J, et al. Relation of left ventricular ejection fraction and functional capacity with metabolism and inflammation in chronic heart failure with reduced ejection fraction (from the MIMICA Study). Am J Cardiol 2010; 105: 977-83. [CrossRef]

27. Zouridakis EG, Garcia-Moll X, Kaski JC. Usefulness of the blood lymphocyte count in predicting recurrent instability and death in patients with unstable angina pectoris. Am J Cardiol 2000; 86: 449-51. [CrossRef]

28. Hofmann U, Frantz S. How can we cure a heart "in flame"? A translational view on inflammation in heart failure. Basic Res Cardiol 2013; 108: 356. [CrossRef]

29. Fowler AJ, Agha RA. Neutrophil/lymphocyte ratio is related to the severity of coronary artery disease and clinical outcome in patients undergoing angiography-the growing versatility of NLR. Atherosclerosis 2013; 228: 44-5. [CrossRef]

30. Windram JD, Loh PH, Rigby AS, Hanning I, Clark AL, Cleland JG. Relationship of high-sensitivity $\mathrm{C}$-reactive protein to prognosis and other prognostic markers in outpatients with heart failure. Am Heart J 2007; 153: 1048-55. [CrossRef]

31. Gudjonsson T, Rahko PS. Relation of "inotropic reserve" to functional capacity in heart failure secondary to ischemic or nonischemic cardiomyopathy. Am J Cardiol 2002; 89: 1057-61. [CrossRef]

32. Lapu-Bula R, Robert A, De Kock M, D'Hondt AM, Detry JM, Melin $\mathrm{JA}$, et al. Relation of exercise capacity to left ventricular systolic function and diastolic filling in idiopathic or ischemic dilated cardiomyopathy. Am J Cardiol 1999; 83: 728-34. [CrossRef] 